14

\title{
Возможности использования комбинированных оптических и АСМ исследований альбумина
}

\author{
() М.Э. Бузоверя, И.В. Шишпор, Ю.П. Щербак
}

Саровский фризико-технический институт филиал Национального исследовательского ядерного университета «МИФИ», 607186 Саров, Нижегородская обл., Россия

๑ e-mail: ira.shishpor@yandex.ru

(Поступило в Редакцию 14 марта 2017 г.)

Приведены результаты комплексного исследования 10\% водного раствора сывороточного альбумина человека методами оптической и атомно-силовой микроскопии. Выявлена тонкая структура основных структур фаций альбумина (стекловидной матрицы, конкреций) и интерпретированы некоторые наблюдаемые структурные эффекты с точки зрения полимерного материаловедения.

DOI: $10.21883 /$ JTF.2018.02.45424.2242

\section{Введение}

В последние годы благодаря появлению нанотехнологий диагностика в медицине продвинулась на существенно новый уровень - в мир наноструктур. Интерес к биополимерам повышается не только у специалистов медико-биологического профиля, но и технических специалистов, работающих в области наноматериаловедения $[1,2]$. Атомно-силовая микроскопия (АСМ) в настоящее время становится одним из самых перспективных методов изучения структурных особенностей макромолекул. Она позволяет получать изображения объектов с высоким разрешением в условиях, при которых макромолекулы не подвергаются жесткой обработке. АСМ дает возможность не только визуализировать объекты на молекулярном уровне, но и увидеть трехмерную структуру микромира.

В настоящее время активно развивается новое диагностическое направление в медицине - функциональная морфология биожидкостей (ФМБ). Фактически метод заключается в исследовании структур различных биожидкостей с помощью оптического микроскопа. Несмотря на то, что данная технология разрешена для применения в клинической практике Федеральной службой по надзору в сфере здравоохранения и социального развития (Разрешение ФС № 2009/155 от 15 июня 2009 г.) и используется в практической медицине, вопросы механизма структурообразования пленок биожидкостей все еще находятся в стадии изучения.

Морфология поверхности пленок тесно связана с реальной структурой и механизмом ее структурообразования. Поэтому в материаловедении традиционно уделяется большое внимание исследованиям морфологии, являющейся важнейшим диагностическим признаком. В ранее проводимых нами исследованиях были предложены подходы к интерпретации изображений фаций из растворов биополимеров на примере альбумина $[3,4]$, рассмотрена реологическая модель пленкообразования фаций [5]. Однако недостаточная разрешающая спо- собность оптического микроскопа и слабая контрастность изображений, получаемых из белковых растворов и некоторых биологических жидкостей, вызывает трудности в интерпретации наблюдаемых структурных эффектов. В связи с этим считаем целесообразным расширить возможности функциональной морфологии биожидкостей с помощью АСМ.

На сегодняшний день имеется достаточное количество работ по применению методов АСМ в биологических и медицинских исследованиях [6-8]. Однако большинство их них в основном нацелено на разработку методов выделения, фиксации и получения тех или иных объектов для их визуального наблюдения. При этом мало внимания уделяется интерпретации, анализу и количественному описанию наблюдаемых структур.

Цель настоящей работы - не только получение АСМ изображений (сканов) биологических жидкостей, но и проведение их осознанного анализа.

\section{Экспериментальная часть}

В настоящей работе использовалась модельная среда $-10 \%$ водный раствор сывороточного альбумина человека (САЧ) (ФГУП „НПО „Микроген“ МЗ РФ г.Нижний Новгород). Оптические исследования проводились на программно-аппаратном комплексе Морфо на базе микроскопа Полам. Рельеф и морфологические характеристики поверхности исследовали методом АСМ с использованием микроскопа Solver Next производства ОАО НТ-МДТ г. Зеленоград. Все измерения проводились на воздухе при нормальных условиях в полуконтактном режиме сканирования (tapping-mode), кантилеверы серии NSG10/W 2 C. Скорость сканирования $0.6 \mathrm{~Hz}$, размер сканов от $0.3 \times 0.3 \mu \mathrm{m}$ до $90 \times 90 \mu \mathrm{m}$. Анализ АСМ сканов с помощью пакета программ для анализа изображений Nova для C3M Solver Next в настоящей работе не приводится. 


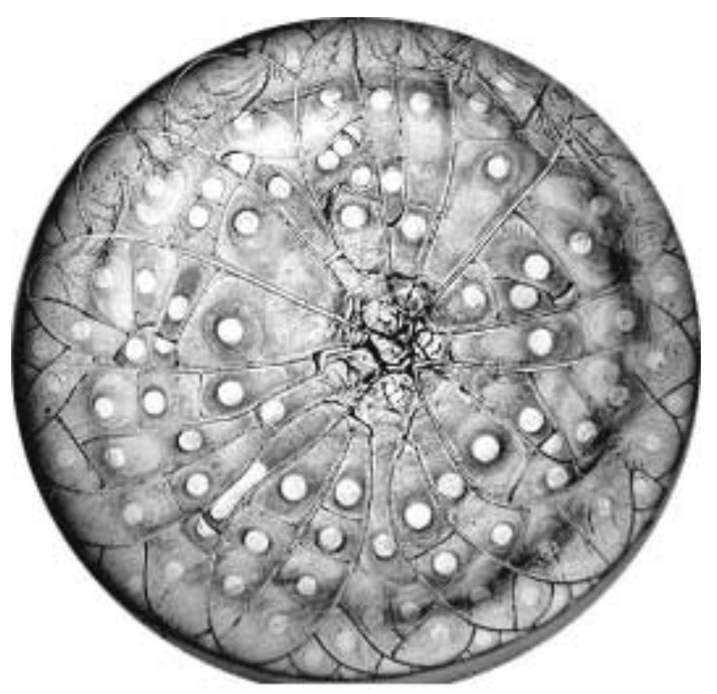

$a$

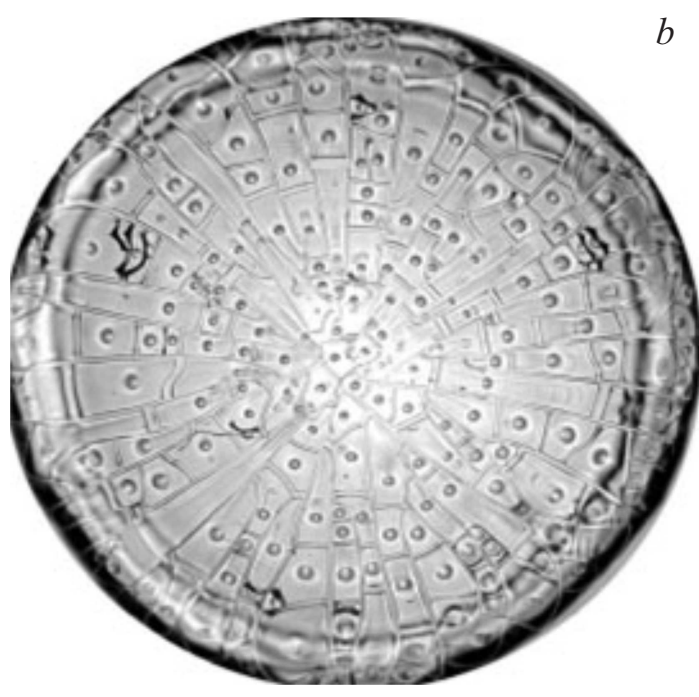

Рис. 1. Фации биожидкостей: $a-$ сыворотка крови человека, $b-10 \%$ водный раствор сывороточного альбумина.

\section{Результаты и обсуждение}

На рис. 1 представлены изображения фаций биожидкости (сыворотки крови человека) и модельной среды (10\% водный раствор сывороточного альбумина), полученные с помощью оптического микроскопа.

В состоянии нормы при физиологическом соотношении белков, солей и других веществ образуется упорядоченная равновесная структура капли в виде высокоорганизованных структур - доменов (в терминах ФМБ отдельностей). Образованию однородных структурных единиц и их упорядочению, по-видимому, способствует сбалансированный состав и регулярное строение молекулярных цепей. Отдельность является основным структурным элементом фации сыворотки крови здорового человека. Это область с четко выраженными границами раздела: в центре бесструктурной стекловидной матрицы находится матовое сферическое включение (в терминах ФМБ - конкреция). Отличие конкреции по цвету от материала матрицы свидетельствует о фазовом разделении веществ в области отдельности. По морфологии фации в виде непрерывной матричной фазы с равномерно расположенными в ней включениями второй фазы можно предположить, что в норме сыворотка крови представляет собой двуфазный студень (студень 2 типа). Ниже приводятся основания, которыми мы руководствовались при выборе этой рабочей гипотезы.

Исследование механизма структурообразования сыворотки крови проводилось на модельной среде $-10 \%$ водном растворе САЧ. Учитывая полимерность и полиэлектролитную природу белка, в работе [4] было высказано предположение, что $10 \%$ САЧ представляет собой макрогель. Согласно классификации С.П. Папкова [9], к полимерным системам более корректно применить термин „студень“, а к биологическому объекту - студень 2 типа. Студень 2 типа - это система с незавершенным расслоением, состоящая из высоковязкой полимерной фазы, играющей роль матрицы, с включением участков низковязкой фазы. Для студней этого типа характерно, что при частичном разрушении под действием внешнего механического воздействия или при неотрелаксировавших внутренних напряжениях создается разветвленная система трещин, что способствует слиянию участков низко концентрированной фазы и отделению ее от студня (вынужденный синерезис).

Вынужденный синерезис нам удалось наблюдать при дегидратации 10\% САЧ в режиме видеосъемки на аппаратно-программном комплексе Морфо. На рис. 2 видно, что формирование конкреции в отдельную фазу идет только после растрескивания фации по границам раздела домена.

До появления первых трещин $(\tau=17 \mathrm{~min})$ капля представляла собой матовую жидкость. Из рисунка видно, что с $\tau=21 \mathrm{~min}$ начинается лавинное растрескивание фации с образованием разветвленной сети трещин. В результате растрескивания образуется открытая капиллярная система, что приводит к интенсификации процессов испарения воды и расслоению раствора в области доменов, отделенных трещинами: в течение времени $\tau=5 \mathrm{~min}$ происходит отделение низковязкой части раствора в виде „конкреции“. На $\tau=26 \mathrm{~min}$ окончательно сформирована топография поверхности разрушения фации.

Поскольку основными структурными элементами фаций являются трещины, конкреции разной формы и размера, бесструктурная/стекловидная матрица, области для АСМ исследований выбирали в привязке к основным структурам фаций оптического уровня.

В настоящей работе представлены результаты исследования стекловидной матрицы и конкреций.

При исследовании фаций 10\% САЧ методами оптической микроскопии структура выражена слабо (рис. 1). 


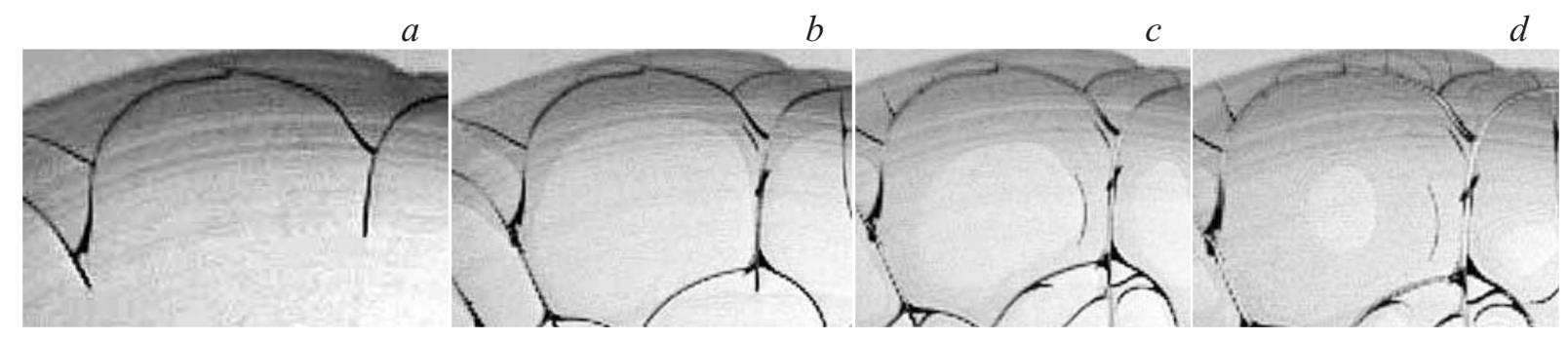

Рис. 2. Образование структуры домена в процессе дегидратации (с начала момента испарения капли): $a-$ через 17, $b-$ через $21, c$ - через $24, d-$ через $26 \mathrm{~min}$.
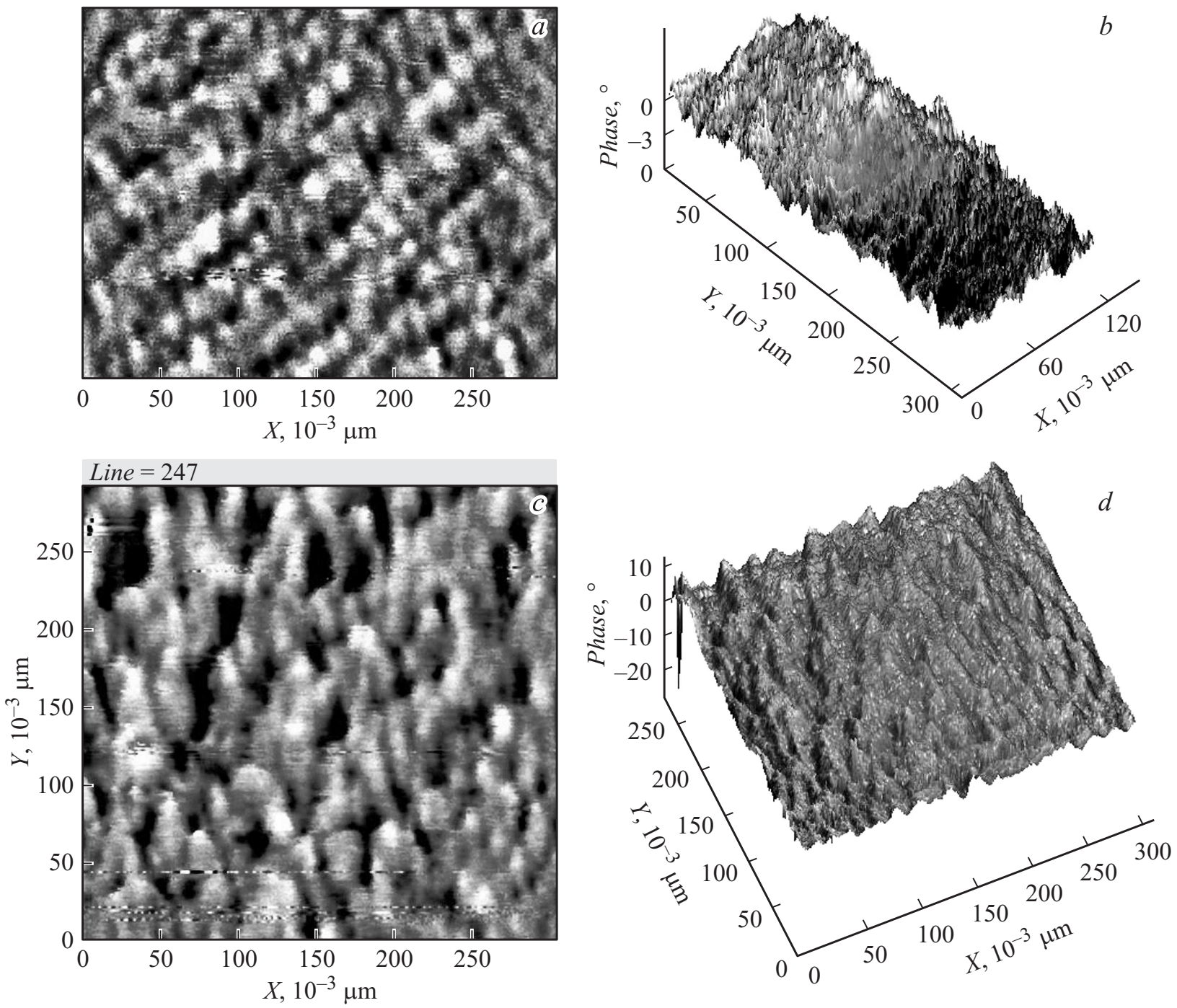

Рис. 3. АСМ изображение фаций $10 \%$ САЧ $(0.3 \times 0.3 \mu \mathrm{m}): a$ - топография матрицы, $2 \mathrm{D} ; b$ - матрица, режим фазового контраста, $3 \mathrm{D} ; c-$ топография конкреции, 2D; $d-$ конкреция, режим фазового контраста, 3D.

Исследования фаций 10\% САЧ методом АСМ на разных масштабных уровнях (размеры сканов от $90 \times 90$ до $0.3 \times 0.3 \mu \mathrm{m})$ позволили наблюдать различные структурные особенности фаций альбумина. Уменьшение площади сканирования позволило различить тонкую структуру поверхности с упорядоченным расположением частиц.
На АCM сканах размером $0.3 \times 0.3 \mu \mathrm{m}$ приведены характерные структуры матрицы и конкреции (рис. 3). Основной структурной единицей являются глобулы частицы сферической формы белого цвета. Темная часть изображений соответствует мягкой гидрофильной матрице. 

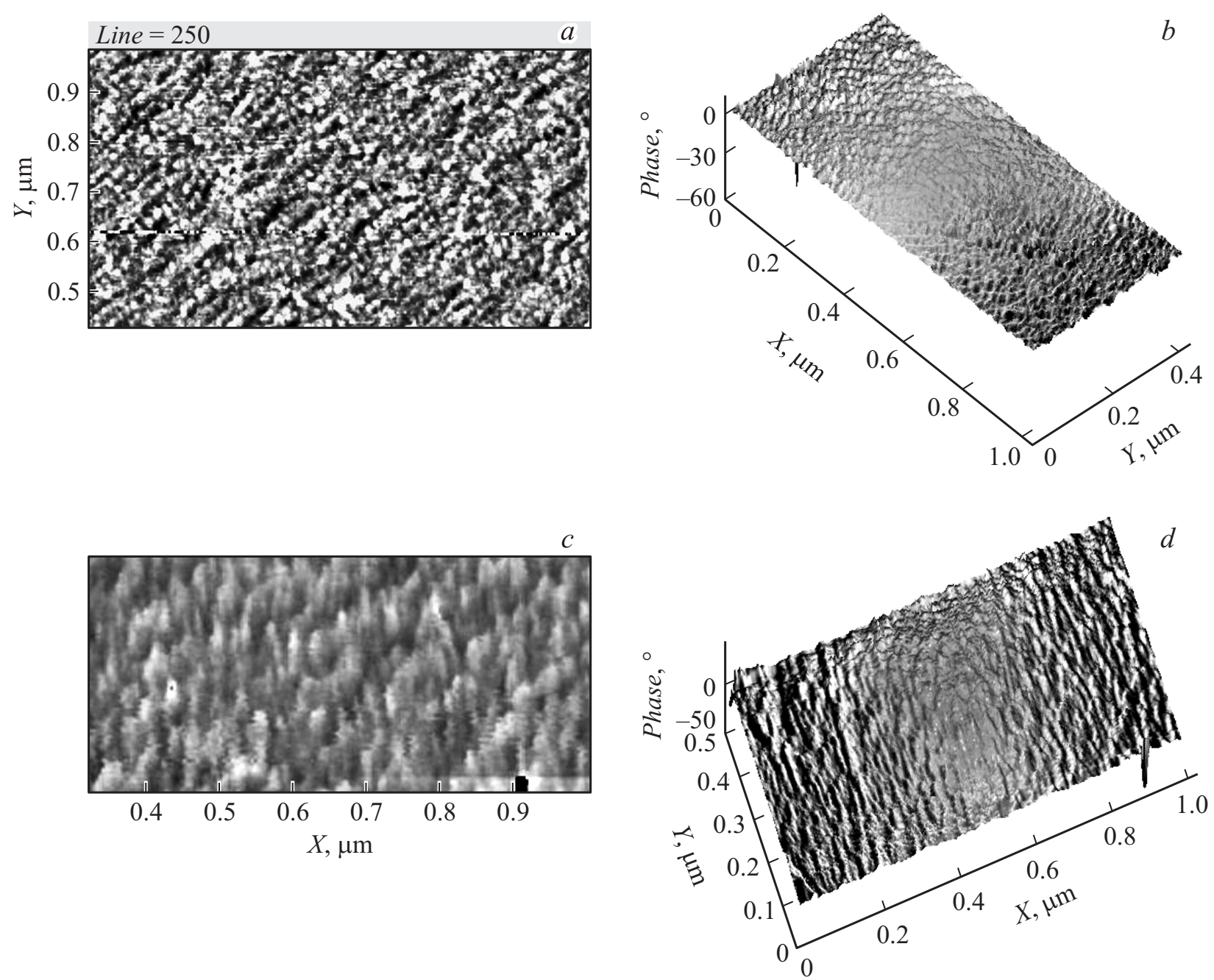

Рис. 4. АСМ изображения $10 \%$ САЧ $(1.0 \times 1.0 \mu \mathrm{m}): a-$ топография матрицы, $2 \mathrm{D} ; b-$ матрица, режим фазового контраста, 3D; $c$ - топография конкреции, 2D; $d-$ конкреция, режим фазового контраста, 3D.

Сравнение тонкой структуры матрицы и конкреций показывает, что материал матрицы более однороден. В нем наблюдается тенденция упаковки глобул в слои. Глобулы по большей части не касаются друг друга, поскольку гидрофильные части макромолекул образуют оболочку и обеспечивают поддержание определенных расстояний между частицами (рис. $3, a, b)$. Материал конкреций более рыхлый, глобулы организованы в короткие цепочки (рис. $3, c, d)$.

На АCM сканах $1.0 \times 1.0 \mu \mathrm{m}$ в материале матриц также хорошо просматриваются слои из глобул (рис. 4,a). Глобулы в слоях матрицы плотно упакованы без взаимного проникновения. Слои не соприкасаются друг с другом. На 3D-изображении матрицы можно наблюдать формирование кольцевых структур из слоев (рис. $4, b)$. Наличие такого устойчивого взаимодействия между глобулами и слоями обусловливает создание пространственной сетки (каркаса), в которой отдельные элементы ее не имеют кинетической самостоятельности.
Конкреция представляет собой при этом увеличении рыхлое образование (рис. 4,c). Морфологической особенностью этой системы является образование структурных форм в виде коротких цепочек и сферических глобул большего размера - типа набухших глобул.

В конкреции при образовании надмолекулярных структур отслеживается другая тенденция: короткие цепочки образуют отдельные вытянутые замкнутые фигуры с гидрофильным центром (рис. $4, d$ ). Образование структур такого типа может объясняться рыхлостью материала конкреций, что обеспечивает бо́льшую подвижность цепочкам глобул. При проведении сравнительных анализов плоского (2D) и объемного (3D) изображений обращаем внимание, что белым включениям соответствуют выступы, а темным впадины.

На сканах размером $10 \times 10 \mu \mathrm{m}, \quad 30 \times 30 \mu \mathrm{m}$ и $90 \times 90 \mu$ т тонкая структура уже не наблюдается. Для микроструктур фаций этого уровня характерно наличие пор, сколов (рис. 5), волнистость рельефа (рис. 6), что 

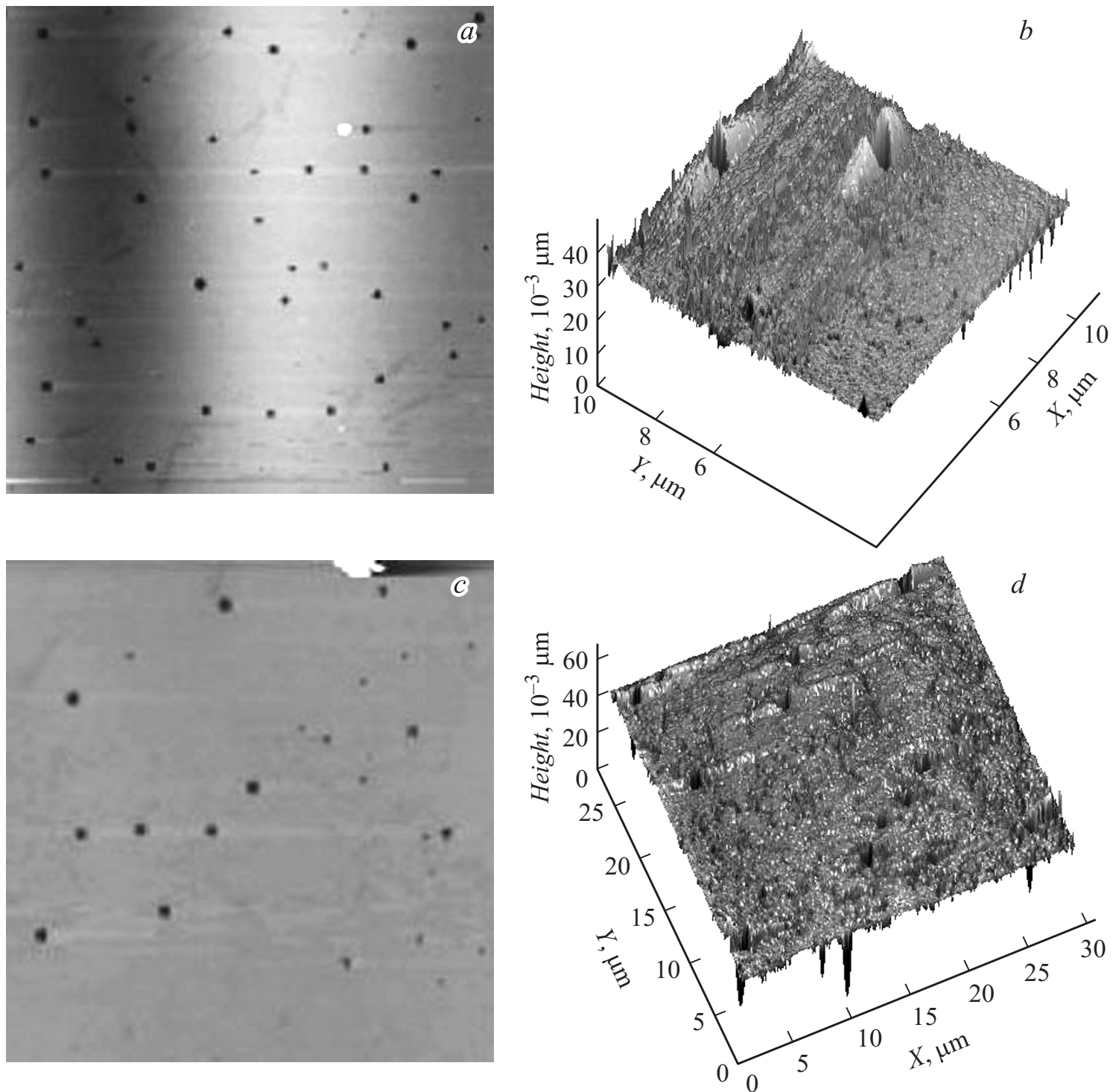

Рис. 5. АСМ изображение $10 \%$ САЧ $(30 \times 30 \mu): a-$ топография матрицы, $2 \mathrm{D} ; b-$ матрица, режим фазового контраста, 3D; $c$ - топография конкреции, 2D; $d-$ конкреция, режим фазового контраста, 3D.
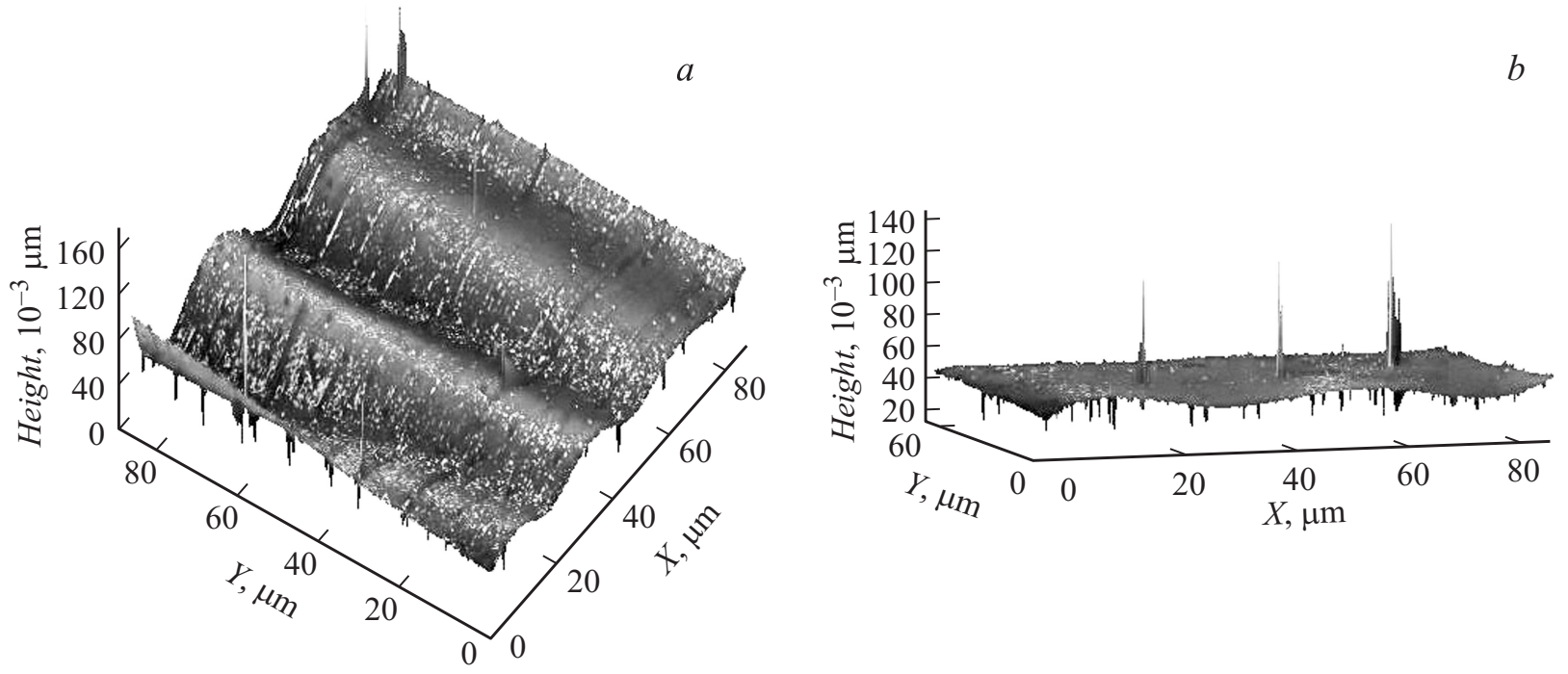

Рис. 6. АСМ изображение $10 \%$ САЧ $(90 \times 90 \mu \mathrm{m}): a-$ топография матрицы, $2 \mathrm{D} ; b-$ матрица, режим фазового контраста, 3D; $c$ - топография конкреции, 2D; $d-$ конкреция, режим фазового контраста, 3D. 
может являться следствием внутренних напряжений, образующихся при дегидратации фации и вызывающих деформацию покрытия или растрескивание. Волнистость поверхности более выражена в матрице. Топология поверхности матрицы отличается глубокими провалами (рис. 6,a). Материал конкреции менее деформирован (рис. $6, b$ ). Возможной причиной может являться большая пластичность материала конкреций, связанная с рыхлостью структуры (рис. 4,b,d), которая обеспечивает большую подвижность надмолекулярным структурам высшего уровня.

При сопоставлении структур разного масштабного уровня наблюдается следующая тенденция: компактные глобулы $(0.3 \times 0.3 \mu \mathrm{m})-$ слои глобул $(1.0 \times 1.0 \mu \mathrm{m})-$ волнистость матрицы $(90 \times 90 \mu \mathrm{m})$; рыхлая глобула цепочки глобул - менее волнистый рельеф конкреции. Такое структурное состояние материала фаций может свидетельствовать о том, что стекловидная матрица, которая является каркасом студня, - концентрированный нетекучий раствор, а конкреция - более разбавленный подвижный раствор САЧ.

\section{Заключение}

Знание особенностей материала на оптическом уровне позволило эффективно использовать атомно-силовой микроскоп для получения дополнительной информации о структуре белковой пленки, подтвердить и интерпретировать ранее наблюдаемые структурные эффекты в САЧ. Сравнение результатов оптических и АСМ исследований взаимно дополняют друг друга и дают более полное представление о механизмах структурообразования фаций биожидкостей.

В настоящей работе представлена небольшая часть экспериментального материала АСМ исследований САЧ, однако даже этот материал показывает большие возможности метода в изучении белковых систем и биожидкостей. Информация АСМ исследований биожидкостей может стать в дальнейшем базовой, „калибровочной информацией для однозначной интерпретации последующих данных оптической микроскопии без привлечения АCM.

Работа выполнена при поддержке программы повышения конкурентоспособности НИЯУ МИФИ.

\section{Список литературы}

[1] Герасименко А.Я., Дедкова А.А., Ичкитидзе Л.П., Подгаецкий В.М., Пономарева О.В., Тавризова М.А. // Нанотехника. 2012. № 3. С. 39-45.

[2] Глухова O.E. // Нано- и микросистемная техника. 2012. № 9. C. 34-39.

[3] Бузоверя М.Э., Шишпор И.В., Потехина Ю.П., Щербак Ю.П. // ЖТФ. 2012. Т. 82. Вып. 7. С. 123-128.

[4] Бузоверя М.Э., Шишпор И.В., Щербак Ю.П. // ЖТФ. 2012. Т. 82. Вып. 9. С. 87-94.
[5] Бузоверя М.Э., Балакшина М.А. // Медицинская физика. 2003. № 2 (18). C. 39-42.

[6] Амантаева Л.С., Аюпова А.К. Исследование морфологии и микроструктуры фаций биологической жидкости с помощью атомно-силовой микроскопии // www.webiris.spls.nsc.ru. Методы и технологии получения графенов и квантоворазмерных структур. Астрахань. 2011. C. $13-17$.

[7] Яхно Т.А. // ЖТФ. 2015. Т. 85. Вып. 11. С. 30-37.

[8] Плескова С.Н. Атомно-силовая микроскопия в биологических и медицинских исследованиях: Уч. пособие. Долгопрудный: Издательский Дом Интеллект, 2011. 184 с.

[9] Папков С.П. Студнеобразное состояние полимеров. М.: Химия, 1974. $256 \mathrm{c}$ 